\title{
Strategies For Targeting Chronic Myeloid Leukaemia Stem Cells
}

This article was published in the following Dove Press journal:

Blood and Lymphatic Cancer: Targets and Therapy

\author{
Giovanna Carrà \\ Antonio Cartellà \\ Beatrice Maffeo \\ Alessandro Morotti iD \\ Department Of Clinical And Biological \\ Sciences, University Of Turin, Orbassano \\ I0043, Italy
}

\begin{abstract}
Chronic Myeloid Leukaemia is a myeloproliferative disorder driven by the $\mathrm{t}$ $(9 ; 22)$ chromosomal translocation coding for the chimeric protein BCR-ABL. CML treatment represents the paradigm of molecular therapy of cancer. Since the development of the tyrosine kinase inhibitor of the BCR-ABL kinase, the clinical approach to CML has dramatically changed, with a stunning improvement in the quality of life and response rates of patients. However, it remains clear that tyrosine kinase inhibitors (TKIs) are unable to target the most immature cellular component of CML, the CML stem cell. This review summarizes new insights into the mechanisms of resistance to TKIs.
\end{abstract}

Keywords: chronic myeloid leukaemia, stem cells, tyrosine kinase inhibitors

\section{Introduction}

Chronic Myeloid Leukaemia (CML) is the paradigm of bench-to-bedside translational research. ${ }^{1-6} \mathrm{CML}$ was among the first cancers to be clearly associated with a genetic lesion, namely the Philadelphia Chromosome, able to generate the chimeric BCR-ABL protein. A plethora of studies with cellular and murine models ${ }^{7}$ converged on the assumption that one single oncogenic gene - BCR-ABL - can drive a potent leukaemogenic signal. ${ }^{3}$ For this reason, BCR-ABL has been intensively studied as a perfect druggable target, leading to the development of imatinib, which quickly raised the clinical arena. ${ }^{8} \mathrm{CML}$ remains the most successfully treated disease with a TKI, ${ }^{9}$ while in other cancers, responses to other specific TKIs are less pronounced. Therefore, understanding the unique biological features of CML should provide new insights into the management of other cancers. In this respect, resistance to TKIs has been generally considered a consequence of the insensitivity of cancer stem cells to these drugs ${ }^{10}$ and, therefore, CML remains a perfect battlefield to investigate biological behaviours of these elusive cells. ${ }^{11} \mathrm{~A}$ lot of evidence has clearly demonstrated that CML stem cells remain unaffected by BCR-ABL TKIs, as extensively reviewed. ${ }^{10,12-14}$ In particular, TKIs are able to enter CML stem cells, to inhibit BCR-ABL, but are not able to promote their apoptosis. ${ }^{14}$

The resistance of CML stem cells to TKIs is a very challenging issue that has been investigated in great depth over the years. ${ }^{15}$ Resolving this problem may not affect CML patients, ${ }^{16}$ who highly benefit from TKI therapy, but may significantly improve our knowledge on leukaemia stem cells, and may improve cancer therapies in general, specifically in those tumours where kinase inhibitors or other molecular approaches fail to achieve convincing clinical results.

This review focuses on mechanisms that affect CML stem cells.
Correspondence: Alessandro Morotti Department Of Clinical And Biological Sciences, University Of Turin, Regione Gonzole 10, Orbassano 10043, Italy Email alessandro.morotti@unito.it 


\section{Cooperating Oncogenes}

For many years, various groups have focused their attention on different pathways that may cooperate with BCR-ABL or may act independently from BCR-ABL in promoting resistance of CML stem cells to TKIs. Here, we will review the most well-known pathways.

\section{NF-kB}

The contribution of the NF-kB signalling pathway has been intensively investigated in CML, and in many other cancers. ${ }^{17} \mathrm{NF}-\mathrm{kB}$ is a transcriptional pathway able to promote various biological processes, favouring cell growth, survival, metastatization and resistance to chemotherapy. ${ }^{18}$ The most common form of NF-kB is the heterodimer $\mathrm{p} 65 / \mathrm{p} 50$, which becomes entrapped in the cytoplasm by the IkB-alpha protein, therefore blocking its transcriptional activity. Upon stimulation, the IkB-alpha protein is phosphorylated at serine residues by the IKKkinase complex, promoting its proteosomal degradation, and enabling NF-kB to shuttle into the nucleus. Various studies have attributed an essential role for NF-kB in BCR-ABL-mediated signalling, ${ }^{19,20}$ as we have also recently reviewed. ${ }^{17}$

Besides playing a pivotal role in the bulky population of CML cells, NF-kB has been also investigated in the stem cell compartment. In particular, two groups have shown that CML stem cells are able to produce and secrete both transforming growth factor- $\beta$ (TGF- $\beta)^{21,22}$ and tumour necrosis factor- $\alpha(\mathrm{TNF}-\alpha),{ }^{23}$ which - in turn support the survival status of the same cells. While these observations suggest that NF-kB can play a remarkable role in stem cells, it is not known whether NF-kB inhibitors may play a specific role in promoting CML stem cell eradication.

\section{Hedgehog Pathway}

Among the many pathways able to modulate stem cell maintenance, hedgehog signalling undoubtedly plays a pivotal role. ${ }^{24}$ Three Hedgehog homologues, namely Desert (DHH), Indian (IHH) and Sonic (SHH), bind to the hedgehog receptor - Patched (Ptc) - promoting cell proliferation and survival in a complex mechanism. While the DHH and IHH pathways have been found to be deregulated in various tumours, SHH signalling has been found to be altered in CML and in leukaemia progenitor cells. Targeting this signalling pathway offers a chance to eliminate CML stem cells, while sparing normal haematopoietic stem cells (HSC). ${ }^{25}$ However, to our knowledge, to date, no data from clinical trials have been published with Hedgehog inhibitors in the CML context.

\section{Beta-Catenin}

The Wnt/ $\beta$-catenin pathway is, historically, a major stem cell pathway, able to modulate both quiescence and maintenance, as extensively reviewed. ${ }^{26}$ It was demonstrated that $\beta$-catenin is involved in various aspects of CML biology, including maintenance of CML stem cells, thus promoting the study of the beta-catenin pathway as a druggable pathway in CML. ${ }^{27}$

\section{PP2A}

The tumour suppressor PP2A has been extensively studied in the context of CML stem cells. In particular, BCR-ABL was shown to inhibit the phosphatase activity of PP2A and its reactivation was found to be associated with a marked growth suppression and apoptosis induction. ${ }^{28}$

Remarkably, a PP2A activator named FTY720 (2amino-2-[2-(4-octylphenyl)ethyl]-1,3-propanediol hydrochloride) displayed potentially relevant implications from a therapeutic standpoint. ${ }^{29,30}$ Similar conclusions were achieved with the clinically validated PP2A inhibitors LB100 and LB102. ${ }^{31}$

\section{Additional Pathways}

Various signal transduction pathways have been shown to modulate BCR-ABL signalling ${ }^{8,32}$ and to promote resistance to TKI in a BCR-ABL independent manner. Among them, the $\mathrm{CK} 2^{33,34}$ and $\mathrm{Alox} 5^{35}$ pathways, along with others, were also associated with the possibility of specific inhibition. It should, however, be noted that most of these pathways have not been investigated in CML stem cell settings.

\section{Tumour Suppressors}

While no tumour suppressors have been consistently found mutated or deleted in the chronic phase of CML, in recent years, various tumour suppressors have been found to be functionally inactive in CML, as we have previously reviewed. ${ }^{36}$ Identifying inactive tumour suppressors and the mechanisms of inactivation may open new therapeutic opportunities. Indeed, restoring the function of an inactive tumour suppressor may represent a strong pro-apoptotic signal.

\section{PML}

The promyelocytic leukaemia (PML) tumour suppressor protein is an essential component of nuclear bodies and is 
involved in various cellular processes. PML has been shown to play an important role in regulating CML stem cells. ${ }^{37}$ PML is a key regulator of the quiescence of these cells, irrespective of the BCR-ABL signal. The relevance of these observations has been associated with the ability of arsenic trioxide to target PML to degradation. Arsenic trioxide has been demonstrated to promote the exit of CML stem cells from the quiescent status, rendering these cells susceptible to apoptosis. For this rational, clinical trials are still ongoing.

\section{PTEN}

PTEN is a tumour suppressor involved in regulating various cellular processes, such as the maintenance of genomic stability, cell survival, migration, proliferation and metabolism. ${ }^{38}$ While originally described as a phosphatase, able to dephosphorylate PIP3, it also displays phosphatase-independent functions. HSC rely on functional PTEN, as extensively studied. ${ }^{39,40}$ In addition, PTEN integrity is mandatory in CML. ${ }^{41}$ The involvement of PTEN in CML is strictly connected to its correct cellular compartmentalization. We observed that, while in CML progenitor cells PTEN is mostly expressed in the cytoplasm, in the CML stem cell compartment, PTEN is retained in the nuclear pool. ${ }^{42}$ Regulating PTEN compartmentalization depends on a functional PML/ HAUSP network, which is maximized in the stem cell compartment. Shuttling of PTEN is indeed associated with changes in cellular behaviours of various cancers. ${ }^{42,43}$ PTEN cellular compartmentation can be modulated by arsenic -trioxide, which affects the PML/HAUSP network, as we previously described. More recently, strategies for targeting the Enhancers of zeste homologue 2 (EZH2), a core catalytic subunit of polycomb repressive complex (PRC2) were shown to modulate PTEN expression in the stem cell compartment, with important therapeutical implications. ${ }^{44}$

\section{FoxO}

Forkhead box subgroup $\mathrm{O}$ (FoxO) is a family of transcription factors (TFs) that play an essential role in regulating cancer stem cells. ${ }^{45}$ As described for PTEN and $\mathrm{p} 53$, FOXOs are mainly deregulated through functional modification of cellular compartmentalization. It has been widely demonstrated that inhibition of FoxO1 and 3a, through cytoplasmic shuttling, supports the growth and inhibition of cell death in CD34+ CML cells. Conversely, leukaemia-initiating cells (LICs) are enriched in FoxO3a nuclear localization mediated by a decrease in Akt phosphorylation. ${ }^{46,47}$

\section{Morgana}

Morgana/chp-1 plays an essential role in mouse embryonic development, involved in the regulation of centrosome duplication and genomic stability. ${ }^{18,48}$ Morgana binds to ROCKI and ROCK II, favouring inhibition of ROCKII kinase activity. Recently, we have demonstrated that morgana \pm mice developed a fatal myeloproliferative disorder, resembling atypical CML. ${ }^{49}$ In an extended analysis, we also demonstrated that some CML patients may also display reduced morgana protein levels in the most immature cellular compartment. Therefore, ROCK activity was increased in these patients with a reduced response to TKI treatment.

\section{TP53}

TP53 is one of the most studied and well-known tumour suppressors. ${ }^{50,51}$ The role of p53 in CML was originally assessed when searching for genetic inactivation. TP53 was indeed discovered to be mutated/deleted in a fraction of CML blast crisis. ${ }^{52}$ However, it was also clear that the role of $\mathrm{p} 53$ in cancer is more complex, including functional inactivation through delocalization and post-translational modifications.

P53 has been shown to be functionally inactivated through direct binding with IkB-alpha in the CML context. ${ }^{53}$ More recently, by investigations with proteomics, transcriptomics and network analyses, p53 was shown to be deregulated in the stem cell compartment, together with c-Myc. ${ }^{54}$ Pharmacological modulation of both p53 and c-Myc levels has been associated with a marked induction in CML stem cell apoptosis.

\section{Epigenetics And Modifiers}

Histone deacetylase inhibitors (HDACi) are epigenetic modifiers that, in vitro, promote growth arrest and apoptosis of myeloid tumour cells. ${ }^{55}$ For this reason, many HDACi have been tested in CML and in CML stem cells, ${ }^{56}$ and various trials have been designed to test HDCA in association with TKI. To our knowledge, no relevant data have, however, been published following these trials.

Yet, epigenetic reprogramming remains a challenging topic in CML stem cells, as recently observed with EZH2. ${ }^{57}$ Taken together, these data suggest that further investigations are necessary to identify the best epigenetic modifiers in CML and the best combinatorial approach.

\section{Stem Cell Metabolism}

Cellular metabolism reprogramming is an emerging hallmark for cancer survival and cancer stem cell biology. ${ }^{58}$ While normal cells use glucose to produce energy by mitochondrial 
oxidative phosphorylation, cancer cells have been shown to increase glucose uptake and promote aerobic glycolysis, originally described as the Warburg effect. This metabolic shift has also been described in CML, where it appears to be therapeutically modulated. ${ }^{59}$ The mTOR pathway has been extensively studied as a major determinant of the anabolic and catabolic processes in normal and cancer cells, ${ }^{60}$ and the mTOR pathway has also been intensively studied in the CML setting. ${ }^{61}$ The kinase - AMPK - has been described as an essential regulator of $\mathrm{mTOR}$ and cellular metabolism and shown to play an important role in CML pathogenesis ${ }^{62}$ and resistance to TKIs. ${ }^{63}$ Notably, AMPK appeared to be targetable in CML. ${ }^{64}$ Finally, and in agreement with the metabolic reprogramming of CML cells, antidiabetic drugs have also been shown to play important roles in this disease. In addition, Metformin, ${ }^{65,66}$ glitazones have been recently studied due to their ability to target CML stem cells. ${ }^{67,68}$

\section{microRNAs}

Various microRNAs (miRNA) have been reported to play a role in CML and, in particular, in the stem cell compartment: ${ }^{69}$ miR-126, ${ }^{70}$ miR-29a-3p, miR-494-3p and miR-660-5p, ${ }^{71}$ and others. More recently, a challenging hsa-mir183/EGR1/E2F1 axis has been reported to directly control CML stem cell behaviour. $^{72}$ Most of these miRNAs have been extensively reviewed elsewhere. ${ }^{69,73-77}$

\section{Cluster Of Differentiation}

Various biomarkers defined as Cluster of Differentiation (CD) have been recognized as specifically expressed in the stem cell compartment. ${ }^{78}$ The cytokine targeting surface enzyme dipeptidylpeptidase-IV (DPPIV/CD26) has been shown to be mostly expressed in the stem cell compartment of CML. ${ }^{78-83}$ Interestingly, CD26 expression appears to be associated with the expression of Polycomb BMI1 protein. ${ }^{84}$ The IL2 receptor CD25 was also shown to be over-expressed in CML cells and - in particular - in the stem cell compartment. ${ }^{85-87}$ While the function of most of these biomarkers remains to be defined in the CML stem cell population, selective expression in these cells may offer a challenging therapeutic implication. Monoclonal antibodies may possibly be developed to specifically target these CD and potentially reach the stem cells of CML.

\section{Stroma}

Interaction of HSC and leukaemia stem cells with bone marrow microenvironments is indispensable for the initiation, maintenance, and progression of CML, and may also affect the sensitivity to therapies. ${ }^{88}$ Furthermore, the role of the stem cell niche in CML leukaemogenesis has been investigated in-depth, highlighting the role of $\mathrm{Cxcl12}$ in the regulation of quiescence of CML. ${ }^{89}$

\section{Autophagy}

Autophagy is a process that is evolutionally conserved to allow recycling of cytoplasmic components through the formation of the autophagosome. These vesicles are driven into lysosomes where they are degraded. ${ }^{90,91}$ Inhibiting autophagy has been shown to play an important role in cancer therapy. ${ }^{92}$ In line with these observations, autophagy inhibitors have been tested as strategies to target CML stem cells alone ${ }^{93}$ or in combination with mTOR inhibitors $^{61}$ and PARP inhibitors. ${ }^{94}$

\section{Immune System}

Aberrant immune-inhibitory responses have been observed in CML patients at diagnosis, ${ }^{95}$ and the immune cellular context has been shown to impact CML therapy ${ }^{96}$ and/or affect immune surveillance. ${ }^{97}$ Similarly, TKIs have been shown to affect the immune system. ${ }^{98}$ Various cytokines known to play a role in the immune system, such as CXCR2 and CXCL4, have been shown to regulate the survival of CML stem cells. ${ }^{99}$ While further investigations are needed in this context, these observations indicate a pivotal role of the immune system in each phase of CML maintenance and, therefore, suggest the variegation of therapeutical implications. In this respect, following the increase in the use of Chimeric Antigen Receptor - engineered $\mathrm{T}$ cells - in the clinical scenario, it was also shown that CAR-T directed toward IL1RAP could represent an efficient approach for targeting CML stem cells. ${ }^{100}$ In addition, checkpoint inhibitors have been discussed as potential relevant targets in CML therapy. ${ }^{101}$

Parallel to the role of the immune system, the intriguing role of inflammation (a mixture of immune system regulators and cytokines) has also been investigated as a determinant for CML stem cell maintenance and/or development. ${ }^{102}$

\section{Discussion}

In this review we have reported various pathways and/or mechanisms that have been recognized to modulate CML stem cell behaviour. For each of these pathways, specific inhibitors have been identified, allowing the proposal of a combinatorial therapy with TKIs with the aim of eradicating CML stem cells. Various clinical trials have been designed for this purpose, ${ }^{10}$ but results are still pending. Data obtained from the clinical scenario will allow identification of 
pathways with relevant roles in the CML stem cell compartment from the plethora of cooperating pathways. CML response rates suggest that combinatorial therapies will only be proposed to those patients resistant to TKIs; however, deciphering mechanisms of insensitivity of CML stem cells to TKIs may shed new light on how to efficiently treat other cancers. It is worth noting that other Philadelphia-positive types of Leukaemia, such as Acute Lymphoblastic Leukaemia, are much less sensitive to BCR-ABL TKIs, and the reason is far from being understood. Moreover, other cancers with other active tyrosine kinases did not respond to specific TKIs with the same efficacy described for CML. Knowing the correct approach for targeting stem cells should enhance the response rates in various tumours.

\section{Acknowledgment}

The authors wish to thank all members of the Division of Internal Medicine - Haematology at the San Luigi Hospital for helpful discussions.

\section{Disclosure}

The authors report no conflicts of interest in this work.

\section{References}

1. Freireich EJ, Wiernik PH, Steensma DP. The leukemias: a halfcentury of discovery. $J$ Clin Oncol. 2014;32:3463-3469. doi:10.1200/JCO.2014.57.1034

2. Goldman JM. Chronic myeloid leukemia: a historical perspective. Semin Hematol. 2010;47:302-311. doi:10.1053/j.seminhematol.2010. 07.001

3. Melo JV, Barnes DJ. Chronic myeloid leukaemia as a model of disease evolution in human cancer. Nat Rev Cancer. 2007;7:441453. doi: $10.1038 / \mathrm{nrc} 2147$

4. Chereda B, Melo JV. Natural course and biology of CML. Ann Hematol. 2015;94 Suppl 2:S107-S121. doi:10.1007/s00277-0152325-z

5. Apperley JF. Chronic myeloid leukaemia. Lancet. 2015;385:14471459. doi:10.1016/S0140-6736(13)62120-0

6. Lambert GK, Duhme-Klair A-K, Morgan T, Ramjee MK. The background, discovery and clinical development of BCR-ABL inhibitors. Drug Discov Today. 2013;18:992-1000. doi:10.1016/ j.drudis.2013.06.001

7. Sontakke P, Jaques J, Vellenga E, Schuringa JJ. Modeling of chronic myeloid leukemia: an overview of in vivo murine and human xenograft models. Stem Cells Int. 2016;2016:1625015. doi:10.1155/2016/1625015

8. Saglio G, Morotti A, Mattioli G, et al. Rational approaches to the design of therapeutics targeting molecular markers: the case of chronic myelogenous leukemia. Ann N Y Acad Sci. 2004;1028:423431. doi:10.1196/annals. 1322.050

9. Hochhaus A, Larson RA, Guilhot F, et al. Long-term outcomes of imatinib treatment for chronic myeloid leukemia. $N$ Engl $J$ Med. 2017;376:917-927. doi:10.1056/NEJMoa1609324

10. Morotti A, Panuzzo C, Fava C, Saglio G. Kinase-inhibitor-insensitive cancer stem cells in chronic myeloid leukemia. Expert Opin Biol Ther. 2014;14:287-299. doi:10.1517/14712598.2014.867323
11. Zhou H, Xu R. Leukemia stem cells: the root of chronic myeloid leukemia. Protein Cell. 2015;6:403-412. doi:10.1007/s13238015-0143-7

12. Holyoake TL, Vetrie D. The chronic myeloid leukemia stem cell: stemming the tide of persistence. Blood. 2017;129:1595-1606. doi:10.1182/blood-2016-09-696013

13. Inoue A, Kobayashi CI, Shinohara H, et al. Chronic myeloid leukemia stem cells and molecular target therapies for overcoming resistance and disease persistence. Int $J$ Hematol. 2018;108:365-370. doi:10.1007/s12185-018-2519-y

14. Corbin AS, Agarwal A, Loriaux M, Cortes J, Deininger MW, Druker BJ. Human chronic myeloid leukemia stem cells are insensitive to imatinib despite inhibition of BCR-ABL activity. J Clin Invest. 2011;121:396-409. doi:10.1172/JCI35721

15. Soverini S, Mancini M, Bavaro L, Cavo M, Martinelli G. Chronic myeloid leukemia: the paradigm of targeting oncogenic tyrosine kinase signaling and counteracting resistance for successful cancer therapy. Mol Cancer. 2018;17:49. doi:10.1186/s12943-018-0780-6

16. Ross DM, Hughes TP, Melo JV. Do we have to kill the last CML cell? Leukemia. 2011;25:193-200. doi:10.1038/leu.2010.197

17. Carrà $\mathrm{G}$, Torti $\mathrm{D}$, Crivellaro $\mathrm{S}$, et al. $\mathrm{BCR}-\mathrm{ABL} / \mathrm{NF}-\mathrm{\kappa B}$ signal transduction network: a long lasting relationship in philadelphia positive leukemias. Oncotarget. 2016;7:66287-66298. doi:10.186 32/oncotarget. 11507

18. Fusella F, Seclì L, Busso E, et al. The IKK/NF- $\mathrm{kB}$ signaling pathway requires Morgana to drive breast cancer metastasis. Nat Commun. 2017;8:1636. doi:10.1038/s41467-017-01829-1

19. Hsieh M-Y, Van Etten RA. IKK-dependent activation of NF- $\mathrm{KB}$ contributes to myeloid and lymphoid leukemogenesis by BCRABL1. Blood. 2014;123:2401-2411. doi:10.1182/blood-2014-01547943

20. Cilloni D, Messa F, Arruga F, et al. The NF-kappaB pathway blockade by the IKK inhibitor PS1145 can overcome imatinib resistance. Leukemia. 2006;20:61-67. doi:10.1038/sj.leu.2403998

21. Zhu X, Wang L, Zhang B, Li J, Dou X, Zhao RC. TGF-beta1-induced $\mathrm{PI} 3 \mathrm{~K} / \mathrm{Akt} / \mathrm{NF}-\mathrm{kappaB} / \mathrm{MMP}$ s signalling pathway is activated in philadelphia chromosome-positive chronic myeloid leukaemia hemangioblasts. J Biochem. 2011;149:405-414. doi:10.1093/jb/mvr016

22. Miyazono K. Tumour promoting functions of TGF- $\beta$ in CML-initiating cells. J Biochem. 2012;152:383-385. doi:10.1093/jb/mvs106

23. Gallipoli P, Pellicano F, Morrison H, et al. F-a production supports CML stem and progenitor cell survival and enhances their proliferation. Blood. 2013;122:6.

24. Fattahi S, Pilehchian Langroudi M, Akhavan-Niaki H. Hedgehog signaling pathway: epigenetic regulation and role in disease and cancer development. J Cell Physiol. 2018;233:5726-5735. doi:10. $1002 /$ jcp. 26506

25. Su W, Meng F, Huang L, Zheng M, Liu W, Sun H. Sonic hedgehog maintains survival and growth of chronic myeloid leukemia progenitor cells through $\beta$-catenin signaling. Exp Hematol. 2012;40:418-427. doi:10.1016/j.exphem.2012.01.003

26. Krishnamurthy N, Kurzrock R. Targeting the Wnt/beta-catenin pathway in cancer: update on effectors and inhibitors. Cancer Treat Rev. 2018;62:50-60. doi:10.1016/j.ctrv.2017.11.002

27. Zhou H, Mak PY, Mu H, et al. Combined inhibition of $\beta$-catenin and Bcr-Abl synergistically targets tyrosine kinase inhibitor-resistant blast crisis chronic myeloid leukemia blasts and progenitors in vitro and in vivo. Leukemia. 2017;31:2065-2074. doi:10.1038/leu.2017.87

28. Neviani P, Santhanam R, Trotta R, et al. The tumor suppressor PP2A is functionally inactivated in blast crisis CML through the inhibitory activity of the BCR/ABL-regulated SET protein. Cancer Cell. 2005;8:355-368. doi:10.1016/j.ccr.2005.10.015

29. Neviani P, Santhanam R, Oaks JJ, et al. FTY720, a new alternative for treating blast crisis chronic myelogenous leukemia and Philadelphia chromosome-positive acute lymphocytic leukemia. $J$ Clin Invest. 2007;117:2408-2421. doi:10.1172/JCI31095 
30. Neviani P, Harb JG, Oaks JJ, et al. PP2A-activating drugs selectively eradicate TKI-resistant chronic myeloid leukemic stem cells. J Clin Invest. 2013;123:4144-4157. doi:10.1172/JCI68951

31. Lai D, Chen M, Su J, et al. PP2A inhibition sensitizes cancer stem cells to ABL tyrosine kinase inhibitors in BCR-ABL+ human leukemia. Sci Transl Med. 2018;10. doi:10.1126/scitranslmed. aan 8735

32. Reckel S, Hamelin R, Georgeon S, et al. Differential signaling networks of Bcr-abl p210 and p190 kinases in leukemia cells defined by functional proteomics. Leukemia. 2017;31:1502-1512. doi:10.1038/leu.2017.36

33. Borgo C, Cesaro L, Salizzato V, et al. Aberrant signalling by protein kinase CK2 in imatinib-resistant chronic myeloid leukaemia cells: biochemical evidence and therapeutic perspectives. $\mathrm{Mol}$ Oncol. 2013;7:1103-1115. doi:10.1016/j.molonc.2013.08.006

34. Morotti A, Panuzzo C, Crivellaro S, et al. ABL inactivates cytosolic PTEN through Casein Kinase II mediated tail phosphorylation. Cell Cycle. 2015;14:973-979. doi:10.1080/15384101.2015. 1006970

35. Chen Y, Hu Y, Zhang H, Peng C, Li S. Loss of the Alox5 gene impairs leukemia stem cells and prevents chronic myeloid leukemia. Nat Genet. 2009;41:783-792. doi:10.1038/ng.389

36. Crivellaro $\mathrm{S}$, Carrà $\mathrm{G}$, Panuzzo $\mathrm{C}$, et al. The non-genomic loss of function of tumor suppressors: an essential role in the pathogenesis of chronic myeloid leukemia chronic phase. BMC Cancer. 2016;16:314. doi:10.1186/s12885-016-2346-6

37. Ito K, Bernardi R, Morotti A, et al. PML targeting eradicates quiescent leukaemia-initiating cells. Nature. 2008;453:1072-1078. doi:1 $0.1038 /$ nature 07016

38. Lee Y-R, Chen M, Pandolfi PP. The functions and regulation of the PTEN tumour suppressor: new modes and prospects. Nat Rev Mol Cell Biol. 2018;19:547-562. doi:10.1038/s41580-018-0015-0

39. Zhang J, Grindley JC, Yin T, et al. PTEN maintains haematopoietic stem cells and acts in lineage choice and leukaemia prevention. Nature. 2006;441:518-522. doi:10.1038/nature04747

40. Yilmaz ÖH, Valdez R, Theisen BK, et al. Pten dependence distinguishes haematopoietic stem cells from leukaemia-initiating cells. Nature. 2006;441:475-482. doi:10.1038/nature04703

41. Peng C, Chen Y, Yang Z, et al. PTEN is a tumor suppressor in CML stem cells and BCR-ABL-induced leukemias in mice. Blood. 2010;115:626-635. doi:10.1182/blood-2009-06-228130

42. Morotti A, Panuzzo C, Crivellaro S, et al. BCR-ABL disrupts PTEN nuclear-cytoplasmic shuttling through phosphorylationdependent activation of HAUSP. Leukemia. 2014;28:1326-1333. doi:10.1038/leu.2013.370

43. Carrà G, Panuzzo $C$, Torti $D$, et al. Therapeutic inhibition of USP7-PTEN network in chronic lymphocytic leukemia: a strategy to overcome TP53 mutated/deleted clones. Oncotarget. 2017;8:35508-35522. doi:10.18632/oncotarget.v8i22

44. Zhou J, Nie D, Li J, et al. PTEN is fundamental for elimination of leukemia stem cells mediated by Gsk126 targeting EZH2 in chronic myelogenous leukemia. Clin Cancer Res. 2018;24:145157. doi:10.1158/1078-0432.CCR-17-1533

45. Liang R, Ghaffari S. Stem cells seen through the FOXO lens: an evolving paradigm. Curr Top Dev Biol. 2018;127:23-47.

46. Naka K, Hoshii T, Muraguchi T, et al. TGF- $\beta$-FOXO signalling maintains leukaemia-initiating cells in chronic myeloid leukaemia. Nature. 2010;463:676-680. doi:10.1038/nature08734

47. Pellicano F, Scott MT, Helgason GV, et al. The antiproliferative activity of kinase inhibitors in chronic myeloid leukemia cells is mediated by FOXO transcription factors. Stem Cells. 2014;32:2324 2337. doi:10.1002/stem. 1748

48. Ferretti R, Palumbo V, Di Savino A, et al. Morgana/chp-1, a ROCK inhibitor involved in centrosome duplication and tumorigenesis. Dev Cell. 2010;18:486-495. doi:10.1016/j.devcel.2009. 12.020
49. Di Savino A, Panuzzo C, Rocca S, et al. Morgana acts as an oncosuppressor in chronic myeloid leukemia. Blood. 2015;125:2245-2253. doi:10.1182/blood-2014-05-575001

50. Zilfou JT, Lowe SW. Tumor suppressive functions of p53. Cold Spring Harb Perspect Biol. 2009;1:a001883. doi:10.1101/cshperspect.a001883

51. Kastenhuber ER, Lowe SW. Putting p53 in context. Cell. 2017;170:1062-1078. doi:10.1016/j.cell.2017.08.028

52. Johansson B, Fioretos T, Mitelman F. Cytogenetic and molecular genetic evolution of chronic myeloid leukemia. Acta Haematol. 2002;107:76-94. doi:10.1159/000046636

53. Crivellaro S, Panuzzo C, Carrà G, et al. Non genomic loss of function of tumor suppressors in CML: BCR-ABL promotes $\mathrm{I} \kappa \mathrm{B} \alpha$ mediated p53 nuclear exclusion. Oncotarget. 2015;6:2521725225. doi:10.18632/oncotarget.4611

54. Abraham SA, Hopcroft LEM, Carrick E, et al. Dual targeting of p53 and c-MYC selectively eliminates leukaemic stem cells. Nature. 2016;534:341-346. doi:10.1038/nature18288

55. Ungerstedt JS. Epigenetic modifiers in myeloid malignancies: the role of histone deacetylase inhibitors. Int J Mol Sci. 2018;19.

56. Zhang B, Strauss AC, Chu S, et al. Effective targeting of quiescent chronic myelogenous leukemia stem cells by histone deacetylase inhibitors in combination with imatinib mesylate. Cancer Cell. 2010;17:427-442. doi:10.1016/j.ccr.2010.03.011

57. Scott MT, Korfi K, Saffrey P, et al. Epigenetic reprogramming sensitizes CML stem cells to combined EZH2 and tyrosine kinase inhibition. Cancer Discov. 2016;6:1248-1257. doi:10.1158/21598290.CD-16-0263

58. Vander Heiden MG, DeBerardinis RJ. Understanding the intersections between metabolism and cancer biology. Cell. 2017;168:657-669. doi:10.1016/j.cell.2016.12.039

59. Kuntz EM, Baquero P, Michie AM, et al. Targeting mitochondrial oxidative phosphorylation eradicates therapy-resistant chronic myeloid leukemia stem cells. Nat Med. 2017;23:1234-1240. doi:10.1038/nm.4399

60. Saxton RA, Sabatini DM. mTOR signaling in growth, metabolism, and disease. Cell. 2017;168:960-976. doi:10.1016/j.cell. 2017.02.004

61. Mitchell R, Hopcroft LEM, Baquero P, et al. Targeting BCRABL-independent TKI resistance in chronic myeloid leukemia by mTOR and autophagy inhibition. J Natl Cancer Inst. 2018;110:467-478. doi:10.1093/jnci/djx236

62. Vakana E, Platanias LC. AMPK in BCR-ABL expressing leukemias. Regulatory effects and therapeutic implications. Oncotarget. 2011;2:1322-1328. doi:10.18632/oncotarget.413

63. Martinez Marignac VL, Smith S, Toban N, Bazile M, Aloyz R. Resistance to dasatinib in primary chronic lymphocytic leukemia lymphocytes involves AMPK-mediated energetic re-programming. Oncotarget. 2013;4:2550-2566. doi:10.18632/oncotarget. 1508

64. Riva B, De Dominici M, Gnemmi I, et al. Celecoxib inhibits proliferation and survival of chronic myelogeous leukemia (CML) cells via AMPK-dependent regulation of $\beta$-catenin and mTORC1/2. Oncotarget. 2016;7:81555-81570. doi:10.18632/ oncotarget.13146

65. Rosilio C, Ben-Sahra I, Bost F, Peyron J-F. Metformin: a metabolic disruptor and anti-diabetic drug to target human leukemia. Cancer Lett. 2014;346:188-196. doi:10.1016/j.canlet.2014.01.0 06

66. Shi R, Lin J, Gong Y, et al. The antileukemia effect of metformin in the Philadelphia chromosome-positive leukemia cell line and patient primary leukemia cell. Anticancer Drugs. 2015;26:913922. doi:10.1097/CAD.0000000000000266

67. Prost S, Relouzat F, Spentchian M, et al. Erosion of the chronic myeloid leukaemia stem cell pool by PPAR $\gamma$ agonists. Nature. 2015;525:380-383. doi:10.1038/nature15248 
68. Rousselot P, Prost S, Guilhot J, et al. Pioglitazone together with imatinib in chronic myeloid leukemia: a proof of concept study. Cancer. 2017;123:1791-1799. doi:10.1002/cncr.v123.10

69. Litwińska Z, Machaliński B. miRNAs in chronic myeloid leukemia: small molecules, essential function. Leuk Lymphoma. 2017;58:1297-1305. doi:10.1080/10428194.2016.1243676

70. Zhang B, Nguyen LXT, Li L, et al. Bone marrow niche trafficking of miR-126 controls the self-renewal of leukemia stem cells in chronic myelogenous leukemia. Nat Med. 2018;24:450-462. doi:10.1038/nm.4499

71. Salati S, Salvestrini V, Carretta C, et al. Deregulated expression of miR-29a-3p, miR-494-3p and miR-660-5p affects sensitivity to tyrosine kinase inhibitors in CML leukemic stem cells. Oncotarget. 2017;8:49451-49469. doi:10.18632/oncotarget.v8i30

72. Pellicano F, Park L, Hopcroft LEM, et al. hsa-mir183/EGR1 mediated regulation of $\mathrm{E} 2 \mathrm{~F} 1$ is required for $\mathrm{CML}$ stem/progenitor cell survival. Blood. 2018;131:1532-1544. doi:10.1182/blood2017-05-783845

73. Nassar FJ, El Eit R, Nasr R. An integrative analysis of microRNA and mRNA profiling in CML stem cells. Methods Mol Biol. 2016;1465:219-241.

74. Alves R, Gonçalves AC, Jorge J, et al. MicroRNA signature refine response prediction in CML. Sci Rep. 2019;9:9666. doi:10.1038/ s41598-019-46132-9

75. Wang K, Xu Z, Wang N, Tian Y, Sun X, Ma Y. Analysis of microRNA and gene networks in human chronic myelogenous leukemia. Mol Med Rep. 2016;13:453-460. doi:10.3892/mmr. 2015.4502

76. Yeh C-H, Moles R, Nicot C. Clinical significance of microRNAs in chronic and acute human leukemia. Mol Cancer. 2016;15:37. doi:10.1186/s12943-016-0518-2

77. Di Stefano C, Mirone G, Perna S, Marfe G. The roles of microRNAs in the pathogenesis and drug resistance of chronic myelogenous leukemia (Review). Oncol Rep. 2016;35:614-624 doi:10.3892/or.2015.4456

78. Warfvinge R, Geironson L, Sommarin MNE, et al. Single-cell molecular analysis defines therapy response and immunophenotype of stem cell subpopulations in CML. Blood. 2017;129:2384 2394. doi:10.1182/blood-2016-07-728873

79. Herrmann H, Sadovnik I, Cerny-Reiterer S, et al. Dipeptidylpeptidase IV (CD26) defines leukemic stem cells (LSC) in chronic myeloid leukemia. Blood. 2014;123:39513962. doi:10.1182/blood-2013-10-536078

80. Valent P, Sadovnik I, Ráčil Z, et al. DPPIV (CD26) as a novel stem cell marker in $\mathrm{Ph}+$ chronic myeloid leukaemia. Eur J Clin Invest. 2014;44:1239-1245. doi:10.1111/eci.2014.44.issue-12

81. Culen M, Borsky M, Nemethova V, et al. Quantitative assessment of the CD26+ leukemic stem cell compartment in chronic myeloid leukemia: patient-subgroups, prognostic impact, and technical aspects. Oncotarget. 2016;7:33016-33024. doi:10.18632/ oncotarget.v7i22

82. Raspadori D, Pacelli P, Sicuranza A, et al. Flow cytometry assessment of CD26+ leukemic stem cells in peripheral blood: a simple and rapid new diagnostic tool for chronic myeloid leukemia Cytometry B Clin Cytom. 2019;96:294-299. doi:10.1002/cyto. b. 21764

83. Bocchia M, Sicuranza A, Abruzzese E, et al. Residual peripheral blood CD26+ leukemic stem cells in chronic myeloid leukemia patients during TKI therapy and during treatment-free remission. Front Oncol. 2018;8:194. doi:10.3389/fonc.2018.00194

84. Galimberti S, Grassi S, Baratè C, et al. The polycomb BMI1 protein is co-expressed with $\mathrm{CD} 26+$ in leukemic stem cells of chronic myeloid leukemia. Front Oncol. 2018;8:555. doi:10.3389/ fonc. 2018.00555
85. Sadovnik I, Herrmann H, Eisenwort G, et al. Expression of CD25 on leukemic stem cells in BCR-ABL1 + CML: potential diagnostic value and functional implications. Exp Hematol. 2017;51:1724. doi:10.1016/j.exphem.2017.04.003

86. Sadovnik I, Hoelbl-Kovacic A, Herrmann H, et al. Identification of CD25 as STAT5-dependent growth regulator of leukemic stem cells in Ph+ CML. Clin Cancer Res. 2016;22:2051-2061. doi:10.1158/1078-0432.CCR-15-0767

87. Kobayashi CI, Takubo K, Kobayashi H, et al. The IL-2/CD25 axis maintains distinct subsets of chronic myeloid leukemia-initiating cells. Blood. 2014;123:2540-2549. doi:10.1182/blood-2013-07517847

88. Mukaida N, Tanabe Y, Baba T. Chemokines as a conductor of bone marrow microenvironment in chronic myeloid leukemia. Int J Mol Sci. 2017;18:1824. doi:10.3390/ijms18081824

89. Agarwal P, Isringhausen S, Li H, et al. Mesenchymal nichespecific expression of Cxcl12 controls quiescence of treatmentresistant leukemia stem cells. Cell Stem Cell. 2019;24:769-784. e6. doi:10.1016/j.stem.2019.02.018

90. Karsli-Uzunbas G, Guo JY, Price S, et al. Autophagy is required for glucose homeostasis and lung tumor maintenance. Cancer Discov. 2014;4:914-927. doi:10.1158/2159-8290.CD-14-0363

91. Ravanan P, Srikumar IF, Talwar, T. Autophagy: The spotlight for cellular stress responses. Life Sci. 2017;188:53-67. doi:10.1016/j. Ifs.2017.08.029

92. Najafi M, Farhood B, Mortezaee K. Cancer stem cells (CSCs) in cancer progression and therapy. J Cell Physiol. 2019;234:83818395. doi:10.1002/jcp.v234.6

93. Baquero P, Dawson A, Mukhopadhyay A, et al. Targeting quiescent leukemic stem cells using second generation autophagy inhibitors. Leukemia. 2018;33:981-994.

94. Liu Y, Song H, Song H, Feng X, Zhou C, Huo Z. Targeting autophagy potentiates the anti-tumor effect of PARP inhibitor in pediatric chronic myeloid leukemia. AMB Express. 2019;9:108. doi:10.1186/s13568-019-0836-z

95. Hughes A, Clarson J, Tang C, et al. CML patients with deep molecular responses to TKI have restored immune effectors and decreased PD-1 and immune suppressors. Blood. 2017;129:11661176. doi:10.1182/blood-2016-10-745992

96. Brück O, Blom S, Dufva O, et al. Immune cell contexture in the bone marrow tumor microenvironment impacts therapy response in CML. Leukemia. 2018;32:1643-1656. doi:10.1038/s41375018-0175-0

97. Tarafdar A, Hopcroft LEM, Gallipoli P, et al. CML cells actively evade host immune surveillance through cytokine-mediated downregulation of MHC-II expression. Blood. 2017;129:199208. doi:10.1182/blood-2016-09-742049

98. Zitvogel L, Rusakiewicz S, Routy B, Ayyoub M, Kroemer G. Immunological off-target effects of imatinib. Nat Rev Clin Oncol. 2016;13:431-446. doi:10.1038/nrclinonc.2016.41

99. Sinclair A, Park L, Shah M, et al. CXCR2 and CXCL4 regulate survival and self-renewal of hematopoietic stem/progenitor cells Blood. 2016;128:371-383. doi:10.1182/blood-2015-08-661785

100. Warda W, Larosa F, Neto Da Rocha M, et al. CML hematopoietic stem cells expressing IL1RAP can be targeted by chimeric antigen receptor-engineered T cells. Cancer Res. 2019;79:663-675. doi:10.1158/0008-5472.CAN-18-1078

101. Ghelli Luserna di Rora A, Iacobucci I, Martinelli G. The cell cycle checkpoint inhibitors in the treatment of leukemias. $J$ Hematol Oncol. 2017;10:77. doi:10.1186/s13045-017-0443-x

102. Baba T, Naka K, Morishita S, Komatsu N, Hirao A, Mukaida N. MIP-1 $\alpha$ /CCL3-mediated maintenance of leukemia-initiating cells in the initiation process of chronic myeloid leukemia. $J$ Exp Med. 2013;210:2661-2673. doi:10.1084/jem.20130112 


\section{Publish your work in this journal}

Blood and Lymphatic Cancer: Targets and Therapy is an international, peer-reviewed, open access journal focusing on blood and lymphatic cancer research, identification of therapeutic targets and the optimal use of preventative and integrated treatment interventions to achieve improved outcomes, enhanced survival and quality of life for the cancer patient. The manuscript management system is completely online and includes a very quick and fair peer-review system. Visit http://www.dovepress.com/testimonials.php to read real quotes from published authors.

Submit your manuscript here: http://www.dovepress.com/blood-and-lymphatic-cancer-targets-and-therapy-journal 